\title{
Earthquake Clustering Relative to Lunar Phases in Taiwan
}

\author{
Cheng-Horng Lin ${ }^{1, \star}$, Yih-Hsiung Yeh ${ }^{1}$, Yuh-Ing Chen ${ }^{2}$, Jann-Yeng Liu ${ }^{3}$, and Kuang-Jung Chen ${ }^{4}$
}

(Manuscript received 21 March 2003, in final form 16 May 2003)

\begin{abstract}
The occurrence of local seismicity recorded in Taiwan for the period of 1973-1991 was converted to lunar time to reassess the notion that some earthquakes may be triggered by tidal forces. The abundant seismicity on the basis of lunar time provides not only sufficient data for statistical analysis but also the most direct and reliable estimation of tidal effects on earthquake triggering. Significant clustering of smaller earthquakes $\left(2.5<M_{L}<5\right)$ was found around Day 14, with clustering around the full moon day being about $30 \%$ higher in frequency than that on other non-full moon days. These phenomena indicate that tidal forces caused by lunar attraction can indeed trigger some smaller earthquakes. On the other hand, the paucity of any correlation between larger earthquakes $\left(M_{L}>5\right)$ and lunar phases indicates that larger earthquakes are barely induced by tidal forces, but predominantly by tectonic forces. No clear correlation between micro-earthquakes $\left(M_{L}<2.5\right)$ and lunar phases suggests that, in addition to tectonic and tidal forces, their occurrence must be primarily associated with other factors.
\end{abstract}

(Key words: Seismicity, Lunar phase, Tidal force, Earthquake triggering)

\section{INTRODUCTION}

Although it has long been acknowledged that tidal forces due to the atraction of the Moon and/or Sun might trigger earthquakes, the inconsistencies in observations over the past few decades have left most seismologists less than convinced of any scientific relationship. Some reports in both regional and local catalogues, however, have shown that tidal forces could be a factor in the triggering of micro-earthquakes in volcanic zones (Rydelek et al. 1998), swarm

\footnotetext{
${ }^{1}$ Institute of Earth Sciences, Academia Sinica, Nankang, Taipei, Taiwan, ROC

${ }^{2}$ Institute of Statistics, National Central University, Chungli, Taiwan, ROC

${ }^{3}$ Institute of Space Science, National Central University, Chungli, Taiwan, ROC

${ }^{4}$ Department of Geosciences, National Taiwan Normal University, Taipei, Taiwan, ROC

${ }^{*}$ Corresponding author address: Prof. C. H. Lin, Institute of Earth Sciences, Academia Sinica, P. O. Box 1-55, Nankang, Taipei, Taiwan, ROC; E-mail: lin@earth.sinica.edu.tw
} 
(Sauck 1975; Klien 1976) and aftershock sequences (Souriau et al. 1982). While the phenomenon of tidal triggering has also been clearly observed in lunar seismicity (Lammlein et al. 1974), it is hard to find any significant correlation between tidal forces and larger earthquakes on the global scale (Shlien and Toksoz 1970; Heaton 1982; Palumbo 1986), or even smaller ones on a more regional one (Knopoff 1964; Vidale et al. 1998).

These inconsistencies might be partially attributed to imprecise calculations and/or the limited scope of earthquake catalogues during the past few decades. For example, some studies (Souriau et al. 1982; Ding et al. 1983) previously pointed out that correlation between forces and earthquake clustering might be distorted because of the complicated nature of tidal force calculations and the absence of appropriate correction procedures. In other words, the calculated tidal phases may significantly differ from the actual. Other researchers (Palumbo 1986; Knopoff 1964) meanwhile reported that some earlier statistical analyses of earthquake clustering might not have been so reliable since the earthquake catalogues used were short on sufficient data.

With the inadequacies of previous research in mind, a more reliable investigative approach into the relationship between the triggering of earthquakes and tidal forces was undertaken here. This study employed a huge number of earthquakes recorded in Taiwan during the 1973 - 1991 period. At first, the occurrence times based on the Gregorian time of all earthquakes were simply converted into lunar days; these were obviously dependent on tidal forces related to lunar attraction. Subsequently, earthquake clusterings were tabulated on the basis of lunar days to determine possible processes involved in the triggering of earthquakes from the Moon's effect. This research has overcome the earlier problems by employing more appropriate estimations of tidal forces along with superior and more abundant cataloguing.

\section{DATA DESCRIPTION AND PROCESS}

The data used in this study were obtained from an earthquake catalogue compiled by the staff at the Institute of Earth Sciences, Academia Sinica, who had regularly maintained the Taiwan Telemetered Seismic Network (TTSN) during the period between 1973 and 1991 (Fig. 1). The seismic network, consisting of 31 short-period analog seismic stations, provided the first high quality modern seismic data in Taiwan to investigate the seismotectonics of the Taiwan area in detail (Tsai et al. 1977). In 1991, this network was combined with the Central Weather Bureau's (CWB) seismic stations to compose the new comprehensive seismic network, the Central Weather Bureau Seismic Network (CWBSN). All of the old TTSN and CWB stations were upgraded to provide 3-component digital recordings, and since then this network has been operated by the CWB.

As Taiwan is located at the strongly convergent boundary between the Eurasian and Philippine Sea plates, a multitude of local earthquakes were recorded by the TTSN during the 1973 - 1991 period (Fig. 1). On average, about 10 to 20 earthquakes were recorded each day, even though on a few days more than one hundred earthquakes occurred (Fig. 2). The most active period of seismic occurrence was found during the 1985 - 1986 period, while little seismic activity was found during the following years (1987 - 1990). In total, more than ninety- 


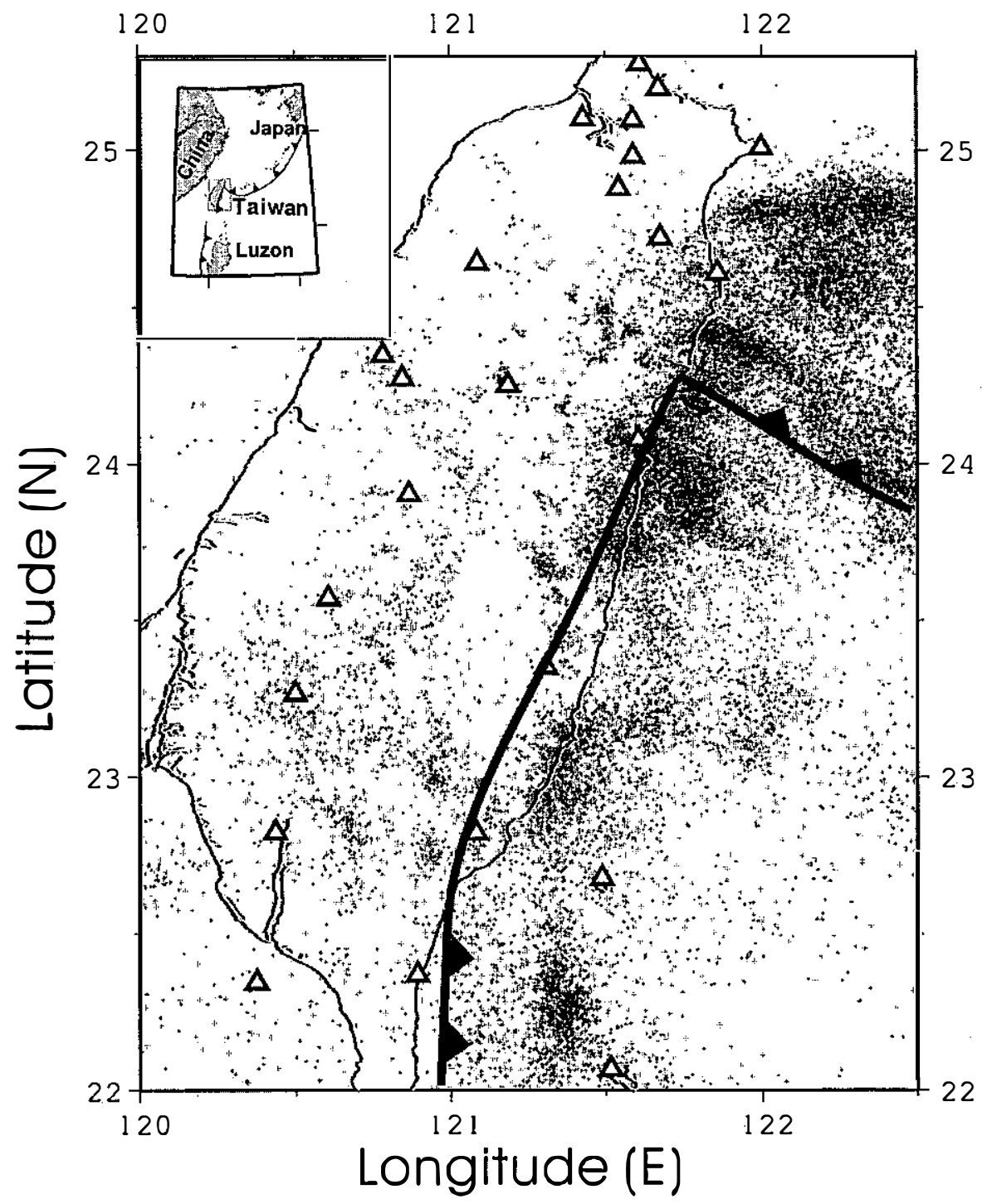

Fig. I. Seismicity (pluses) recorded by the 31 TTSN stations (wiangles) from 1973-1991 in the Taiwan area. Inset map shows the location of Taiwan.

one thousand earthquakes with local magnitudes $\left(\mathrm{M}_{\mathrm{L}}\right)$ between 0.7 and 6.3 were recorded by the TTSN during the 1973 - 1991 period. A typical relationship of the magnitude-frequency was obtained in magnitudes greater than 2.0 (Fig. 3a). The focal depths of earthquakes were ranging from surface down to $200 \mathrm{~km}$, but most of them belong to shallow earthquakes (Fig. $3 b$ ). Such a huge number of earthquakes, each with the reliable characteristics of long record length, completeness and consistency of magnitude determination, provide an ideal regional data set for statistical analysis. In addition, as most earthquakes in Taiwan have been gener- 


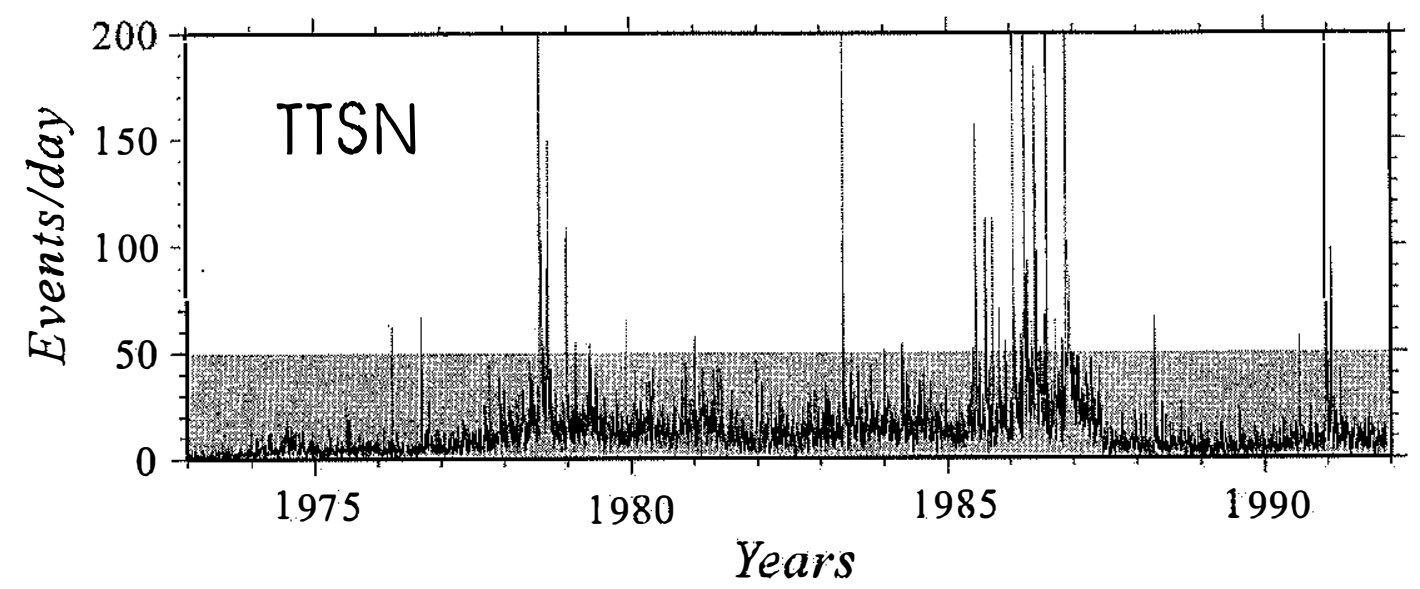

Fig. 2. Histogram of all regional earthquakes recorded in the Taiwan area during the 1973-1991 period. The earthquake data with the daily frequency of less than 50 events/day (gray area) were counted to find the possible relationship between earthquake clustering and lunar phases.

ated under a horizontal compression due to plate convergence, their focal mechanisms are largely represented by thrusting faults (Lin et al. 1985; Yeh et al. 1991).

To identify the possible relationships between lunar phases and earthquake clustering, the occurrence time of each earthquake in the Taiwan monthly catalogues recorded on the Gregorian calendar was converted into the lunar calendar. The first day of the lunar month was simply synchronized with the big-tide day of the new Moon as obtained from the astronomical reports by the Central Weather Bureau (CWB), Taiwan, which still provides the ancient lunar calendar for agricultural purposes even though the Taiwan government has adopted the Gregorian calendar since 1911 . Since the lunar calendar that was very popularly used in ancient civilizations, such as Greek, Roman and Chinese, preserves the length of the lunar month, it provides the most direct and reliable information describing the position of the Moon relative to the Earth. In the 1973 - 1991 period, there were 228 lunar months.

\section{RESULTS AND DISCUSSION}

To evaluate the possible effects of lunar phases on earthquake occurrences of different magnitudes, all of the earthquakes selected in this study were categorized into three groups, namely, larger earthquakes $\left(\mathrm{M}_{\mathrm{L}}>5\right)$, smaller earthquakes $\left(2.5<\mathrm{M}_{\mathrm{L}}<5\right)$ and micro-earthquakes $\left(M_{L}<2.5\right)$. These numbered 109, 42,255 and 49,127, respectively, for a total of 91,491 . The magnitude limitations $\left(2.5<\mathrm{M}_{\mathrm{L}}<5.0\right)$ for separating those earthquakes into three groups were obtained from comparing several possible combinations, such as $2.5<\mathrm{M}_{\mathrm{L}}<4.0,2.5<\mathrm{M}_{\mathrm{L}}<4.5,2$. $5<\mathrm{M}_{\mathrm{L}}<5.0$ and so on. The results from the magnitude limitation $\left(2.5<\mathrm{M}_{\mathrm{L}}<5.0\right)$ show the most significant correlation between the earthquake clustering and tidal forces. Besides, to avoid 

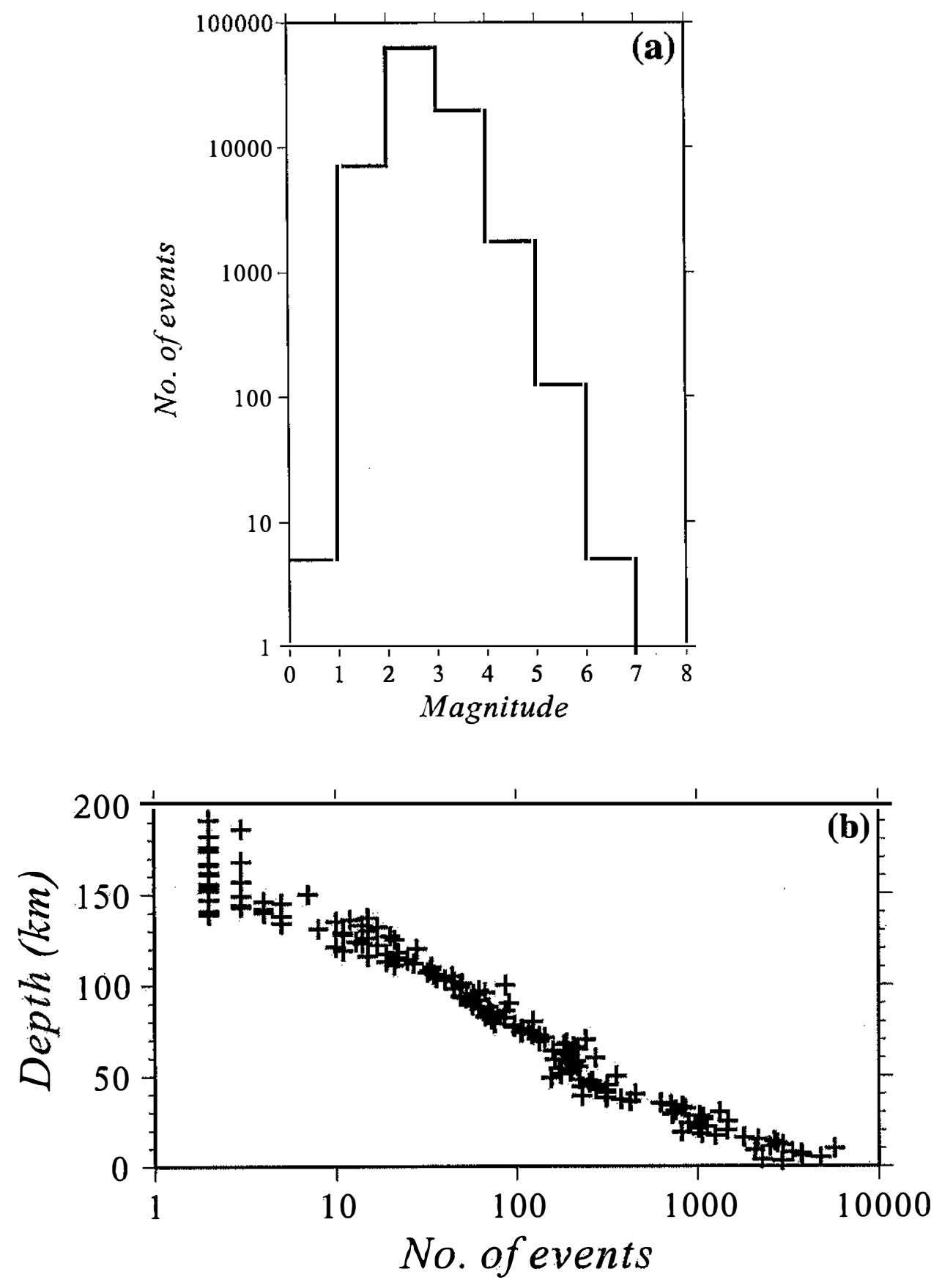

Fig. 3. (a) Histogram of the magnitude-frequency and (b) plot of event number with focal depths of earthquakes in the Taiwan area during the 19731991 period. 
possible effect of short-term burst of seismic activity, such as an earthquake swarm and aftershocks, the earthquake data with the daily frequency of greater than 50 events/day (Fig. 2 ), which is about 2 standard deviations away from the mean value of the daily frequency (10 - 20 events/day), were not counted in the construction of the final earthquake frequency in lunar days. This criterion removes about $5 \%$ of total events from the database. Similar results were also obtained if the cutoff value of the daily frequency was given by 40 or 60 events/day. Finally, the histograms of the occurrences of the accumulated earthquakes tabulated by day of individual lunar months during this period (1973 and 1991) are shown in Fig. 4.

Before the further discussion of the results, a statistical test was applied to evaluate the significance between the earthquake occurrence and lunar phases. The Chi-square goodnessof-test for uniform distribution (Snedecor and Cochran 1989) shows the p-value is 0.029 for larger earthquakes $\left(\mathrm{M}_{\mathrm{L}}>5\right)$ and both $\mathrm{p}$-values are zero for smaller earthquakes $\left(2.5<\mathrm{M}_{\mathrm{L}}<5\right)$ and micro-earthquakes $\left(M_{L}<2.5\right)$. These results show that all of the three groups were not of uniform distribution, indicating some possible correlation between the earthquake occurrence and lunar phases.

\subsection{Larger Earthquakes $\left(M_{L}>5\right)$}

For earthquakes with magnitudes greater than 5 (Fig. 4a), the significant peak in earthquake clustering was found at Day 24, where the earthquake number was greater than the average value plus two standard deviations of all larger earthquakes. No significant correlation between lunar phases and earthquake clusters was found. This result was in basic agreement with previous literature reports (Shlien and Toksoz 1970; Heaton 1982; Palumbo 1986), which demonstrated that any correlation between larger earthquakes and tidal forces was nonexistent on the global scale.

The absence of any significant correlation with tidal forces, in addition to possible biases due to the limited number of larger earthquakes in the present study, might be surprising due to the preconceived notion that larger earthquakes are triggered by tidal forces. It is well accepted that earthquakes occur when stress exceeds a particular critical value on a fault within the crust. A fault that is tectonically pre-sressed to its yield point would therefore be expected to fail when additional stress, such as tidal stress, is applied, as this would raise the total stress above that critical value. However, more recent investigations (McNutt and Beavan 1981; Tsuruoka et al. 1995) have shown that the stress variation $\left(\sim 3 \times 10^{3} \mathrm{~Pa}\right)$ due to tidal forces is considerably less than the stress drop ( $>10 \mathrm{Mpa}$ ) of a larger earthquake with a magnitude greater than 5. Although the "critical state" of an earthquake might be attained from the small magnitude of stress due to tidal forces, one might reasonably conclude that only a minority of all larger earthquakes are, in fact, induced by tides (Shirley 1988).

Another factor to explain why there is no correlation between larger earthquakes and tidal forces might be the strong variation in tectonic forces on the global scale. To be sure, seismicity on the global scale is largely dominated by strong variations in tectonic driving forces in different places. Tectonic forces, rather than tidal forces, are the primary catalysts that trigger earthquakes, even if seismicity may be associated with both of these. Therefore, it is hard to identify any relationship between larger earthquake clustering and tidal forces worldwide. 

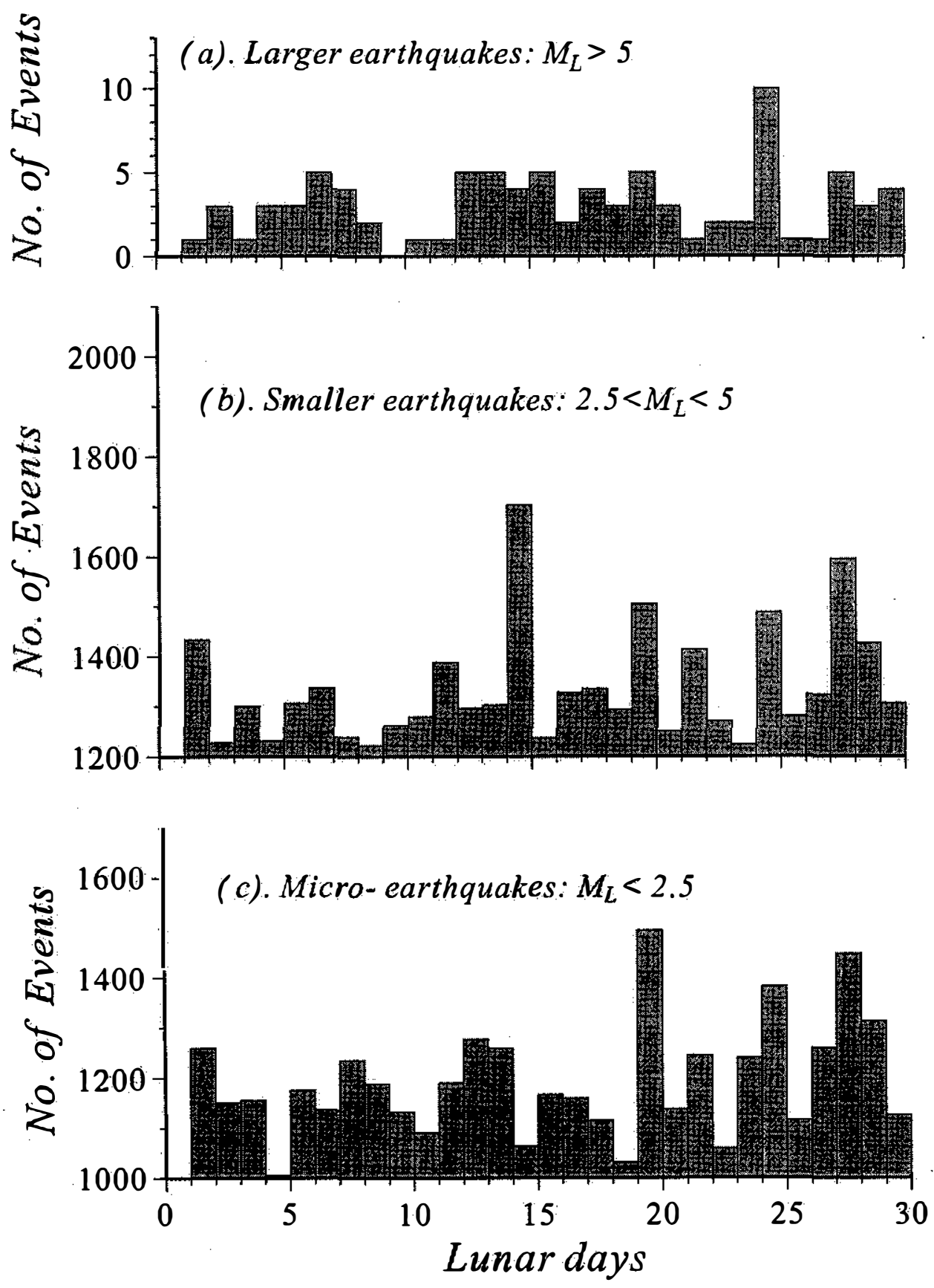

Fig. 4. Histogram of the earthquakes recorded on each lunar day: (a) larger earthquakes $\left(\mathrm{M}_{\mathrm{L}}>5\right)$; (b) smaller earthquakes $\left(2.5<\mathrm{M}_{\mathrm{L}}<5\right)$; and (c) micro-earthquakes $\left(M_{L}<2.5\right)$. Thick and dashed lines mark the average value and two standard deviations, respectively. 


\subsection{Smaller Earthquakes $\left(2.5<\mathrm{M}_{\mathrm{L}}<5\right)$}

Unlike larger earthquakes, smaller ones with magnitudes ranging from 2.5 to 5 were significantly consistent with the period of lunar phases (Fig. 4b). On average, the accumulated seismicity steadily triggered by tectonic forces was about 1300 events/day during the 1973 to 1991 period. Two significant peaks in earthquake clustering were found around Days 14 and 27. The most significant anomaly of the earthquake cluster was found on Day 14 (the full Moon) at which time earthquake frequency was more than 1700 events/day. The earthquake number was greater than the average number plus two standard deviations. In other words, it represented an increase of about $30 \%$ compared with the average number. Another earthquake clustering was found on Day 27 (1600 events/day), or an increase of about 23\%. However, earthquake number did not exceed the average value plus two standard deviations.

The positive correlation between smaller earthquake clustering and lunar phases indicates that tidal forces together with tectonic forces might trigger some smaller earthquakes. Although it is well accepted that tectonic forces have a greater impact on the generation of earthquakes, the frequency of occurrence of smaller earthquakes triggered by tectonic forces in a small-localized area, such as Taiwan, might be very stable during a very short geological time. In contrast, as stated earlier, the Earth's tide with less stress (3,000 Pa) (McNutt and Beavan 1981; Tsuruoka et al. 1995) might be unable to trigger larger earthquakes $\left(M_{L}>5\right)$ whose stress drop is often greater than $10 \mathrm{Mpa}$, whereas tidal forces with such periodic variations might be strong enough to induce smaller earthquakes with local magnitudes $\left(M_{L}\right)$ of only around 3. Thus, some anomalous clustering beyond the background level of smaller earthquakes, which were generated by tectonic forces, might be obtained in local or regional places due to the additional smaller earthquakes riggered by tidal forces. This phenomenon is very similar to lunar seismicity that is significantly consistent with the tidal force (Shlien and Toksoz 1970) because there is no tectonic force in the case of the Moon.

\subsection{Micro-earthquakes $\left(M_{L}<2.5\right)$}

For micro-earthquakes with magnitudes of less than 2.5, the correlation between earthquake clusters and lunar phases was not so clear (Fig. 4c). Several earthquake peaks had been found on Days 19, 24 and 27. Although earthquake clustering (1450 events/day) on Day 27 might have been associated with tidal forces, there was no significant correlation around the full Moon. In addition, some of the earthquake clusterings on Days 19 (1490 events/day) and 24 (1380 events/day) were almost at the same level as Day 27, but they were barely correlative to tidal forces. One of possible explanations is atributed to the absence of the completed dataset (Fig. 3a), in which some micro-earthquakes with magnitudes less than 2.0 might not be recorded by the regional seismic network (TTSN) due to the limitation of station-spacing. Alternatively, the lack of correction between micro-earthquake clusters and lunar phases might indicate that micro-earthquakes are riggered by not only tidal forces but also by such other factors as atmospheric pressure, rainfall, and pore fluid flow in a fault zone with smaller stress variations (Klien 1976). 


\section{CONCLUSIONS}

The presence of earthquake clustering on the lunar periodicity in this study is strongly indicative of the possible physical significance between lunar positioning and earthquake occurrence. For smaller earthquakes $\left(2.5<\mathrm{M}_{\mathrm{L}}<5\right)$, the significant peak of seismic clustering around Day 14 shows that the tidal force due to lunar phases can significantly trigger parts of smaller earthquakes. On the other hand, the absence of any correlation between the larger earthquakes $\left(\mathrm{M}_{\mathrm{L}}>5\right)$ and lunar phases indicates that the larger ones are largely dominated by tectonic rather than tidal forces. No clear correlation between micro-earthquakes $\left(M_{L}<2.5\right)$ and the occurrence of lunar phases implies that in addition to tectonic and tidal forces some other undetermined factors, such as atmospheric pressure, rainfall, and pore fluid flow in a fault zone with smaller stress variations, might induce micro-earthquakes.

Acknowledgments The first author would like to thank colleagues at Institute of Earth Sciences, Academia Sinica for compiled seismic data. The discussion with Drs. Shen, J. J., Lee, J. C., Wang, P. L., Kou, C. H., and Chang, Y. C. are much appreciated as well. This study was also partially supported by the National Science Council and the Central Weather Bureau at Taipei, Taiwan.

\section{REFERENCES}

Ding, Z., J. Jia, and R. Wang, 1983: Seismic triggering effect of tidal stress. Tectonophysics, 93, 319-335.

Heaton, T. H., 1982: Tidal triggering of earthquakes. Bull. Seism. Soc. Am., 72, 2181-2200.

Klien, F. W., 1976: Earthquake swarms and the semidiurnal solid earth tide. Geophys. J. $R$. Astr. Soc., 45, 245-295.

Knopoff, L., 1964: Earth tides as a triggering mechanism for earthquakes. Bull. Seism. Soc. Am., 54, 1865-1870.

Lammlein, D. R., G. V. Latham, J. Dorman, Y. Nakamura, and M. Ewing, 1974: Lunar seismicity, structure and tectonics. Rev. Geophys., 12, 1-21.

Lin, C. H., Y. H. Yeh, and Y. B. Tsai, 1985: Determination of regional principal stress directions in Taiwan from fault plane solutions. Bull Inst. Earth Sci., 5, 105-107.

McNutt, S. R., and R. J. Beavan, 1981: Volcanic earthquakes at Pavlof Volcano correlated with the solid earth tide. Nature, 294, 615-618.

Palumbo, A., 1986: Lunar and solar tidal components in the occuurrence of earthquakes in Italy. Geophys. J. R. Astr. Soc., 84, 93-99.

Rydelek, P. A., P. M. Davies, and R. Y. Koyanagi, 1988: Tidal triggering of earthquake swarms at Kilauea Volcano, Hawaii. J. Geophys. Res., 95, 4401-4411.

Sauck, W. A., 1975: The Brawley, California, earthquake swarm of January, 1975, and riggering by earth tides. Geophys. Res. Lett., 2, 506-509.

Shirley, J. H., 1988: Lunar and solar periodicities of large earthquake: Southern California and Alaska-Aleutian islands seismic region. Geophys. J., 92, 403-420. 
Shlien, S., and M. N. Toksoz, 1970: A clustering model for earthquake occurrences. Bull. Seism. Soc. Am., 60, 1765-1787.

Snedecor, G. W., and W.G. Cochran, 1989: Statistical methods (Eighth Edition), Ames, Iowa: lowa State Press.

Souriau, M., A. Souriau, and J. Gagnepain, 1982: Modeling and detecting interactions between earth tides and earthquakes with application to an aftershock sequence in the Pyrenees. Bull Seism. Soc. Am., 72, 165-180.

Tsai, Y. B., T. L. Teng, J. M. Chiu, and H. L. Liu, 1977: Tectonic implications of the seismicity in the Taiwan region. Mem. Geol. Soc. of China, 2, 13-41.

Tsuruoka, H., M. Ohtake, and H. Sato, 1995: Statistical test of the tidal triggering of earthquakes: contribution of the ocean tide loading effect. Geophys. J. Int., 122, 183-194.

Vidale, J. E., D. C. Agnew, M. J. S. Johnston, and D. H. Oppenheimer, 1998: Absence of earthquake correlation with Earth tides: an indication of high preseismic fault stress rate. J. Geophys. Res., 103, 24, 567-24,572.

Yeh, Y. H., E. Barrier, C. H. Lin, and J. Angelier, 1991: Stress tensor analysis in the Taiwan area from focal mechanism of earthquakes. Tectonophysics, 200, 267-280. 